\section{Consider the octopus}

\author{
Simon Conway Morris
}

7 $\mathrm{t}$ is a scene that would do justice to a horror movie: body clamped against the diver's mask, one tentacle deftly turning off the oxygen supply while others tug relentlessly at the connecting hoses. Despairingly, the diver looks at the octopus and, across an immense phylogenetic gulf, camera eye meets camera eye. If the struggling diver is a biologist he might take some consolation that the glances exchanged depend on a classic example of convergent evolution.

Overwhelmingly, however, the octopus is an encounter with the alien: no hands, but tentacles that can untie surgical silk and clamp with innumerable suckers. Its bulbous body houses an enormous brain, but more than half of the nervous system lies in remote ganglia. Across the body flicker the coruscating patterns of the chromatophores, sometimes freezing the animal into an almost exact replica of the sea-floor, or alternatively transforming itself into a facsimile of the banded sea-snake. Science fiction collides with scientific fact. Are the octopus and its relatives not the best thing we have for a proxy alien? Step a little closer.

The octopus and related cephalopods might seem to exemplify the 'other', but when it comes to reinventing the evolutionary wheel they are dab hands. In addition to those camera eyes, some squid have the reverse arrangement, whereby transparent portals in the body pour bioluminescent light into the inky oceans. Other sensory convergences include a lateral line system, a good approximation of the semicircular canals and superb oculomotor reflexes. The independent evolution of giant axons and a blood-brain barrier are complemented by an impressive list of anatomical convergences. These include cartilage, a closed circulatory system with elastic arteries, a swim-bladder, respiratory proteins (haemocyanin), the famous ink and even a fair stab at a penis.

So, in many ways, cephalopods are honorary fish, but as Andrew Packard (1972) made clear there are still "limits of convergence ${ }^{\prime \prime}$. This point is robustly echoed by Ronald O'Dor \& Dale Webber (1986) whose paper carries a corresponding subtitle "why squid aren't fish". Quite so, but again, step a little closer. Concealed in the body plan are convergences that point to some far more interesting evolutionary principles. Consider those writhing arms. 'One for all, and eight for all'; in principle all are equipotent, but some are evidently employed for one task and others for another (Byrne et al, 2006). This is exemplified by octopuses that stroll bipedally across the lagoon floor. Yet more remarkable are muscular contractions that move in either direction and collide to define pseudo-joints: a rubbery tentacle is transformed into a limb, complete with 'wrist' and 'elbow'. This led Germán Sumbre and colleagues (2005) not only to identify what to some is an apparently surprising functional convergence, but also to suggest that, in the context of any articulated limb, this could be "the optimal design".

Much is also made of the obvious differences in locomotion: myotomal sinuosity compared with jet propulsion in the squid. In the former, the locomotory efficiency depends crucially on the oxidative red muscle and the larger bulk of white muscle. Red muscle is used in routine swimming, whereas the white one springs into action in times of urgent need, and then repays the oxygen debt in just the same way as when the jogger collapses on the park bench and gasps "lactic acid, lactic acid". The squid's mantle muscle holds another surprise. The muscle types are directly analogous to the red and white muscle of fish, with corresponding mitochondrial content and glycolytic activity (Mommsen et al,1981).

But if squid are honorary fish, somewhere, surely, the convergences must break down. Well, let's consider the cephalopod kidney. They are excretory, but do not resemble that of any vertebrate. However, they show something curious: with few exceptions, the kidneys are infested with tiny symbionts, but from two entirely unrelated groups (Furuya et al, 2004). One are the dicyemid mesozoans, which earn the trophy for metazoan simplification, being composed of only about 50 cells. They have abandoned all organs including a nervous system, but intriguingly still employ Pax6. The other group are ciliates and belong to the otherwise obscure chromidinids. Consider this evolutionary conundrum: the only place on the planet where these dicyemids and chromidinids can be found is in places awash with cephalopod urine. Long dismissed as parasitic, they are probably vital to kidney function, and I suspect this is the cephalopods' smart way of constructing a high-performance kidney.

So specific, so precise, so strange is this convergence that I am forcibly reminded of Ramón y Cajal's (1937) contemplation of the insect eye as "a machine so subtilely devised and so perfectly adapted to an end as the visual apparatus" that it provoked him to continue "I must not conceal the fact that $[\ldots]$ I for the first time felt my faith in Darwinism [...] weakened, being amazed and confounded by the supreme constructive ingenuity". So too with the cephalopod kidney, haunted as it is by this symbiotic inevitability.

But if you really want to feel the hairs pricking on your neck, consider the brain of the octopus (Young et al, 1963). Lobate and of quite different construction to the vertebrates, nevertheless once again the similarities emerge not least between its vertical lobe and our hippocampus. Within these neural recesses, consciousness has flickered into existence and, by a separate evolutionary route, the Universe is becoming self-aware.

\section{REFERENCES}

Byrne RA et al (2006) / Comp Psychol 120: 198-204

Furuya $\mathrm{H}$ et al (2004) J Morph 262: 629-643

Mommsen TP et al (1981) Proc Natl Acad Sci USA 78: 3274-3278

O'Dor RK, Webber DM (1986) Can J Zool 64: 1591-1605

Packard A (1972) Biol Rev 47: 241-307

Ramón y Cajal S (1937) Recollections of My Life. Cambridge, MA, USA: MIT Press

Sumbre G et al (2005) Nature 433: 595-596 Young JZ (1963) Proc Zool Soc Lond 140: 229-254

Simon Conway Morris is an evolutionary palaeobiologist at the Department of Earth Sciences, University of Cambridge, Cambridge, UK.

E-mail:sc113@cam.ac.uk

EMBO reports (2011) 12, 182. doi:10.1038/embor.2011.12 